\author{
Asian Development Policy Review \\ $\operatorname{ISSN}(e):$ 2313-8343 \\ $\operatorname{ISSN}(p): 2518-2544$ \\ DOI: $10.18488 /$ journal.107.2021.91.57.68 \\ Vol. 9, No. 1, 57-68. \\ (C) 2021 AESS Publications. All Rights Reserved. \\ URL: www.aessweb.com \\ check for
updates
}

\title{
LIFE EXPECTANCY IN SUB-SAHARA AFRICA: AN EXAMINATION OF LONG-RUN AND SHORT-RUN EFFECTS
}

\author{
D Behiye Cavusoglu ${ }^{1+}$ \\ Obadiah Jonathan \\ Gimba $^{2}$
}

\author{
${ }_{1,2}$ Department of Economics, Near East University, Boulevard, Nicosia, \\ North Cyprus, Turkey. \\ 'Email:behiye.cavusoglu@neu.edu.tr
}

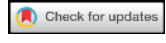

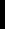

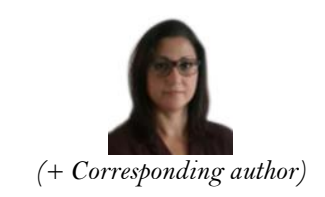

\section{Article History}

Received: 26 February 2021 Revised: 29 March 2021 Accepted: 20 April 2021 Published: 24 May 2021

\section{Keywords \\ Life expectancy Inflation \\ GDP per capita \\ $\mathrm{CO}_{2}$ emission \\ Sub-Saharan Africa \\ Cointegration \\ Food production \\ Human capital.}

JEL Classification: O15; I150.

\begin{abstract}
The realization of the factors that influence life expectancy is crucial for attaining longevity. In this paper, we examine the long-run and short-run determinants of life expectancy in sub-Saharan Africa (SSA). The determining variables include, inflation, Gross Domestic Product (GDP) per capita, Carbon dioxide (CO2) emission, food production, human capital and health expenditure. The estimation technique used are Pedroni cointegration and pool mean group regression. The results from the Pedroni cointegration show that the variables exhibit long-run relationship. The outcome from the pool mean estimation group confirms that in the long-run inflation and $\mathrm{CO} 2$ emission have significantly negative effect on life expectancy while GDP per capita, food production, human capital and health expenditure have a significant and positive influence on life expectancy. It also reveals that in the short-run inflation and food production do not have any impact on life expectancy. The findings recommend that various governments in SSA should increase their public health spending, formulate policies that will discourage $\mathrm{CO} 2$ emission and the use of clean energy and food production should be enhanced through modernized agricultural practices.
\end{abstract}

Contribution/ Originality: This study contributes to existing literature by presenting new stylized facts and results about life expectancy and its determining factors in SSA. It uses the autoregressive distributed lag technique which allows the simultaneous estimation of long-run and short-run coefficients, allowing for objective analysis across time.

\section{INTRODUCTION}

Life expectancy is a measure of the average life span an individual is expected to be lived at birth. All countries desire to have a higher life expectancy because the benefits associated with higher life expectancy are enormous. Longevity allows individuals to contribute more to the economic fortunes of their countries. A low life expectancy can lead to decline in total labour supply. Life expectancy is a reflection of health and socio-economic status of a country. Improved health care which will lead to a higher life expectancy also have a direct impact in stimulating economic growth (Bloom, Sachs, Collier, \& Udry, 1998). An improvement in life expectancy has a positive effect on economic growth in developing countries (Ngangue \& Manfred, 2015).

In 2016, the Organization for Economic Corporation and Development (OECD) countries mean life expectancy stood at 80.1 years. This would have been 67.3 years if a child was born earlier in 1960. In Sub-Saharan Africa 
(SSA), the average life expectancy as at 2016 stood at 60.4 years. While a child born earlier in 1960 would have lived on the average for just 40.4 years.

It is against this background that we want to find out the factors that are responsible for influencing life expectancy in Sub-Saharan Africa. The improvement in life expectancy may be as a result of advancement in medical sciences whereby diseases such as malaria, measles, cholera, pneumonia, small pox etc. that were hitherto deadly are now curable (Cliff, Peter, \& Mathew, 2004). However, in recent times, the world is faced with challenges of cancer, HIV/AIDS, tuberculosis, Ebola. This may likely reverse the gain made so far. McKeown (1997) opined that the fall in mortality rate and the rise in life expectancy was as a result of increase in household income and technological progress.

This study matters because the essence of public health policy in developing economies is to sustain an improve health condition. Hence it is vital to discover components which contributes to individual health status thereby enhancing life expectancy. In some of parts of the SSA for example Botswana and South Africa, the average life expectancy used to be 60 years but has plummeted to between 40 and 45 years. The most productive years are between $40-45$ years. The implication is the loss of valuable workforce which has adverse consequences on the productivity of a nation. The loss of vibrant workforce will also lead to loss of tax revenue. A decline in life expectancy will likely increase the dependency ratio because parents who died at a young age will leave their children under the care of relatives which increases the dependency ratio. These children may be force to work at an early age or even lead to child labor, doing informal jobs to survive instead of being in school. This research is also vital because if sustaining life expectancy is worth pursuing, we need to better understand the drivers of life expectancy in order to orchestrate favorable conditions and public policies.

The key questions this research would seek to answer are:

- What are the socio-economic factors that drives life expectancy in SSA?

- What are the long-run and short-run dynamics of the factors?

The contributions of this paper to literature are as follows: firstly, it presents new stylized facts about life expectancy and its determining factors in SSA. Secondly, it uses the autoregressive distributed lag technique which allows the simultaneous estimation of long-run and short-run coefficients. This allows for objective analysis across time. Thirdly, we present policy recommendations based on evidence that will enhance life expectancy in the SSA.

\section{THEORETICAL REVIEW}

Life expectancy can be linked to the life history theory which admits that events in a human's life such as birth, teenage stage, adulthood and death is reliant on the natural habitat or environment and the strength which an individual draw resources from the environment (Roff, 2002). This theory connects life expectancy to the environment enabling humans to adopt to the environment and make significant contributions in knowledge and skills that will promote longevity.

The Cobb Douglas production function can be used indirectly to explain life expectancy. Suppose an economy $i$ has the following production function with constant returns to scale. We assume there are only two factors, capital and labour.

$y_{i t}=\alpha k_{i t}^{\beta} l_{i t}^{1-\alpha-\beta}$

Where $y_{i t}$ denotes output, $k_{i t}$ denotes capital and $l_{i t}$ denotes labour. $\alpha+\beta \leq 1$. The Cobb Douglas production function is transformed to a health production function by including a term for covariates of socioeconomic determinants of life expectancy. Life expectancy becomes our output. 
$y_{i t}=\left(S_{i t}\right) \alpha k_{i t}^{\beta} l_{i t}^{1-\alpha-\beta}$

Where; $s_{i t}$ is a covariate of socioeconomic determinants of life expectancy.

\section{EMPIRICAL REVIEW}

Kabir (2008) investigate the social and economic factors that influence life expectancy in developing countries using multiple linear regression and probit models. The explanatory variables include per capita GDP, adult illiteracy, urban population, total fertility, population without access to safe drinking water, number of physicians per one hundred thousand people, number of undernourished people. The outcome from the multiple regression shows that number of physicians per one hundred thousand people and the number of undernourished people is significant in influencing life expectancy in developing countries. However, per capita GDP is insignificant in explaining life expectancy. The results from the probit regression reveal that per capita income, adult illiteracy, health expenditure and urbanization may not increase life expectancy. By using a multivariate analysis across nations to find out the factors that affect life expectancy in developing countries. Husain (2002) considered biological, environmental, ecological, socio-economic and regional factors as possible determinants of life expectancy. It was discovered that a positive relationship exists between per capita health expenditure and per capita daily calorie intake. While fertility rate and adult illiteracy rate had a negative relationship with life expectancy.

A rising inflation affects life expectancy substantially. Just as a growing inflation lessen the purchasing power of household, in the long run life expectancy and inflation depicts a negative trend (Grossman, 1972). Literature on life expectancy and unemployment is contentious. Forbes and McGregor (1984) showed that there is a positive association between unemployment and life expectancy in Scotland.

Miller and Frech (2000) analyzed country level OECD data and estimate the regression for life expectancy at ages 40 and 60 years and also pooling data for males and females showed that pharmaceutical spending had a significant and positive effect on life expectancy and this rise with age. They also discovered that unhealthy life style represented by tobacco consumption was not a significant determinant of life expectancy.

Employing a health production function, to determine health status of Sub-Saharan Africa, Fayissa and Gutema (2005) finds that environmental and socio-economic factors such as carbon dioxide emission, urbanization rate, ration of health spending to Gross Domestic Product (GDP), income per capita, illiteracy rate and food availability are determinants of health status. They estimated the model using panel data approach and their outcome indicate a rise in income per capita, food availability and literacy rate is linked to advancement in life expectancy.

Education is viewed as a great importance in determining life expectancy. Literacy enables individuals to have the ability to read, write and develop healthy ethics. Education increases employment chances and income growth. Yavari and Mehrnoosh (2006) examined the effect of socio-economic factors on life expectancy employing multiple regression analysis. They established that there is a positive strong correlation between life expectancy and socioeconomic variables such as per capita income, health expenditures, literacy rate and daily calorie consumption. They also found negative strong correlation between life expectancy and the ratio of people to doctor in African countries.

Keita (2013) applied a panel dataset of Sub-Saharan African countries and analyzed the socioeconomic determinants of life expectancy gain. He employed multiple estimation techniques such as pooling, fixed effect, long difference and system Generalized Method of Moments (GMM). He found that GDP per capita is strongly and positively correlated with life expectancy gain. Similarly, access to improved sanitation, adult literacy and safe 
water was observed to correlate positively with health gain. However, extreme poverty is negatively correlated with health gain but the impact of income inequality on health gain appears uncertain.

Using data on 187 banking crises in 126 countries from 1970 to 2009, Mathijs (2014) finds the impact of financial crises on society. The impact of financial crises on the society goes beyond economic effect such as declining growth and increased unemployment but that of declining life expectancy. He stressed that the likely causes of decline in life expectancy is as a result of increase in stress levels which result to higher incidence of cardiovascular disease, a rise in suicide rate and an increased addiction to drugs and alcohol. He further established a rise in HIV prevalence and poor nutrition in the wake of the crises.

Sede and Ohemeng (2015) provides empirical evidence about socioeconomic determinants of life expectancy in Nigeria employing a VAR and VECM framework. They discovered that established socioeconomic variables such as per capita income, education and government expenditure on health believed to be highly effective in influencing life expectancy of developing countries are not significant in Nigeria.

Monsef and Mehrjardi (2015) studied the determinants of life expectancy in 136 countries from the period 2002 to 2010 , using a panel data approach. Their result shows that unemployment and inflation influence life expectancy negatively while gross capital formation and gross national income affect life expectancy positively.

Bayati, Akbarian, and Kavosi (2013) examined the determinants of life expectancy for 21 Eastern Mediterranean counties using fixed effect model. Their results show that income per capita, education, food availability, urbanization and employment associate positively with life expectancy. Halicioglu (2011) used the Bounds testing method for cointegration to explain the determinants of life expectancy in Turkey. The outcome of the study suggest that food availability and health expenditure enhance longevity. However, smoking was discovered as the main factor for declining life expectancy. Shahbaz, Loganathan, Mujahid, Ali, and Nawaz (2016) contributed to the literature on factors responsible for longevity in Pakistan by including the misery index among many other variables. Their findings reveal a long-run relationship between the variables. Health expenditure, food supply and urbanization promote life expectancy while economic misery and illiteracy causes a decline in life expectancy.

Jaba, Balan, and Robu (2014) analyze the health expenditure and health outcomes for a panel of 175 countries by employing the input-output analysis. They discover a positive and significant relationship exist between life expectancy and health expenditure. Amuka, Asogwa, Ugwuanyi, Omeje, and Onyechi (2018) examine the role of $\mathrm{CO}_{2}$ emission on life expectancy in Nigeria among other factors. Their findings show a positive but insignificant relationship between life expectancy and $\mathrm{CO}_{2}$ emission. This indicates $\mathrm{CO}_{2}$ emission is not responsible for declining life expectancy in Nigeria. Ali and Ahmad (2016) explore the effect of food production, school enlistment, inflation, $\mathrm{CO}_{2}$ emission, population growth and per capita income on life expectancy for the Sultanate of Oman. The study was conducted using ARDL estimation. Their findings suggest food production and school enlistment associate positively with life expectancy and a negative relationship exists between population growth and life expectancy. In the short-run, $\mathrm{CO}_{2}$ emission has a negative and significant relationship with life expectancy. However, inflation and per capita income were insignificant in explaining longevity

\subsection{Stylized Facts}

Figure 1 shows the pattern of the average life expectancy in SSA over the years. It is evident that life expectancy is on a gradual and steady rise. 


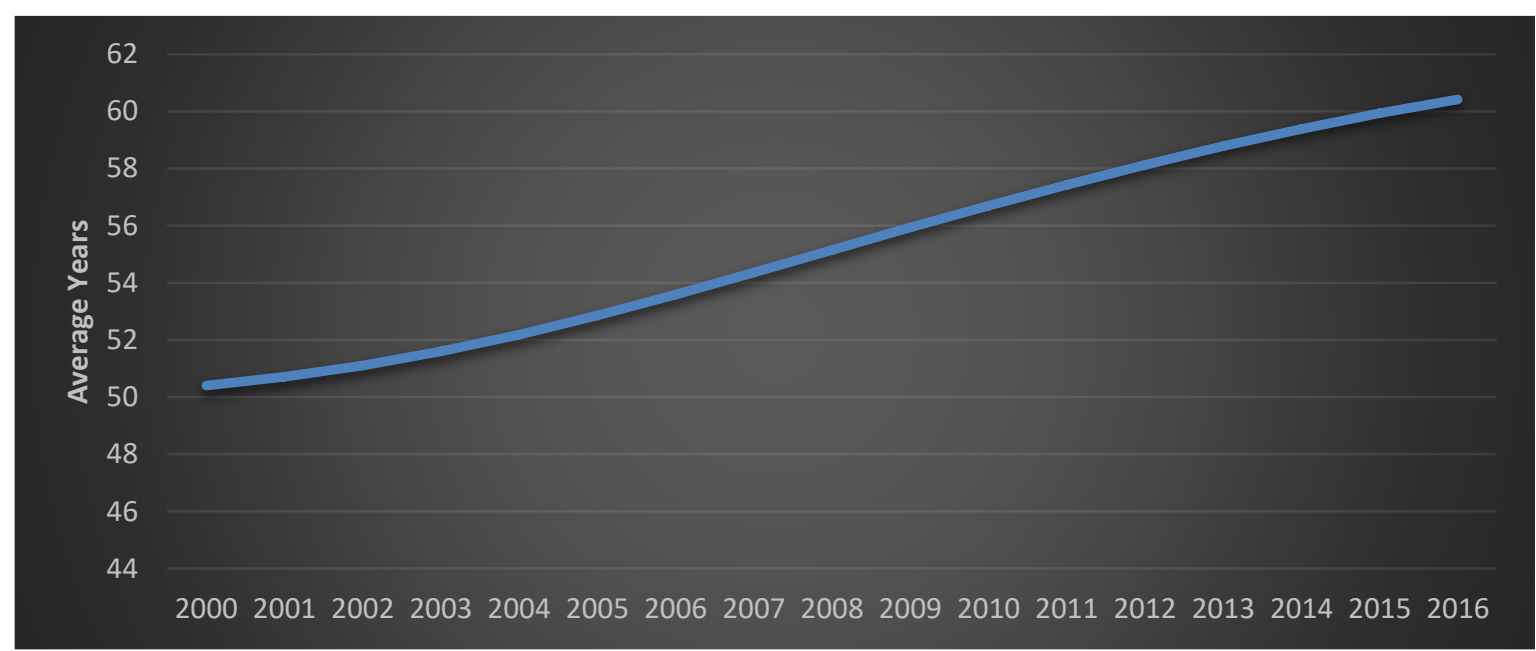

Figure-1. Life Expectancy in Sub Saharan Africa, 2000 - 2016.

Table 1 is the summary statistics for the overall SSA. Within the period of study, life expectancy had an average value of 55.58 years. The mean inflation rate stood at 10.14. An average of $\$ 1991.15$ was the GDP per capita. On the average, 0.694 ton of $\mathrm{CO}_{2}$ was emitted. SSA had an average of 111.56 in the food production index. Human capital index was 1.83 and the mean health expenditure as a percentage of GDP stood at $5.68 \%$

Table-1. Summary Statistics for SSA

\begin{tabular}{c|c|c|c|c}
\hline \multicolumn{6}{|c|}{ Table-1. Summary Statistics for SSA. } & Max \\
\hline Variables & Mean & Std. Dev. & Min & 74.39 \\
\hline LE & 55.58 & 6.91 & 39.44 & 509.8 \\
\hline INF & 10.14 & 29.35 & 4.5 & 10809.65 \\
\hline GDPC & 1991.15 & 2336.77 & 113.56 & 3.82 \\
\hline COE & 0.69 & 0.87 & 0.016 & 206.96 \\
\hline FPI & 111.56 & 25.85 & 44.33 & 2.859 \\
\hline HCI & 1.83 & 0.41 & 1.12 & 20.41 \\
\hline HE & 5.68 & 2.61 & 1.57 & \\
\hline
\end{tabular}

Figure 2 shows the average life expectancy by sub-regions. The Central African sub-region had a mean life expectancy 55.02 years which is slightly lower than the SSA average. The East African sub-region had an average life expectancy of 59.09 years which is above the SSA average. Southern Africa had the lowest average life expectancy among the sub-regions. The average of 52.8 years is far below the average for SSA. The life expectancy in West African sub-region is just slightly below the average for the SSA.

The low mean life expectancy in Southern Africa according to the WHO report 2016 can be attributed to the high incidences of HIV/AIDS and tuberculosis infections in Botswana and South Africa. Other causes low life expectancy includes child and maternal conditions that result to death during child birth, diseases such as stroke, heart diseases, cancer, and chronic lungs diseases. Death as a result of violent crime is also prevalent in South Africa, Mozambique and Zimbabwe.

The rising life expectancy in East Africa can be connected to several factors such as accessibility to surgical care most especially in Kenya and Tanzania. There have been successful partnerships between governments and development partners in curbing the incidence of malaria. About two-third of women are able to give birth with assistance from a skilled worker. The sub-region has been able to achieve wide basic immunization in children.

Table 2 compare the explanatory variables across regions. The West African sub-region had the least inflation rate of $6.93 \%$ while Southern Africa had the highest inflation rate of $13.17 \%$. GDP per capita was highest in the in Southern Africa and lowest in West Africa. 1.14 tons of $\mathrm{CO}_{2}$ was emitted in Southern Africa making it the highest whereas West Africa had the least $\mathrm{CO}_{2}$ emission. Food production was highest in West Africa and lowest in East Africa. Human capital index based on years of schooling and education was highest in Southern Africa and lowest in 
West Africa. Central Africa sub-region recorded the highest health expenditure to GDP with East Africa having the least.

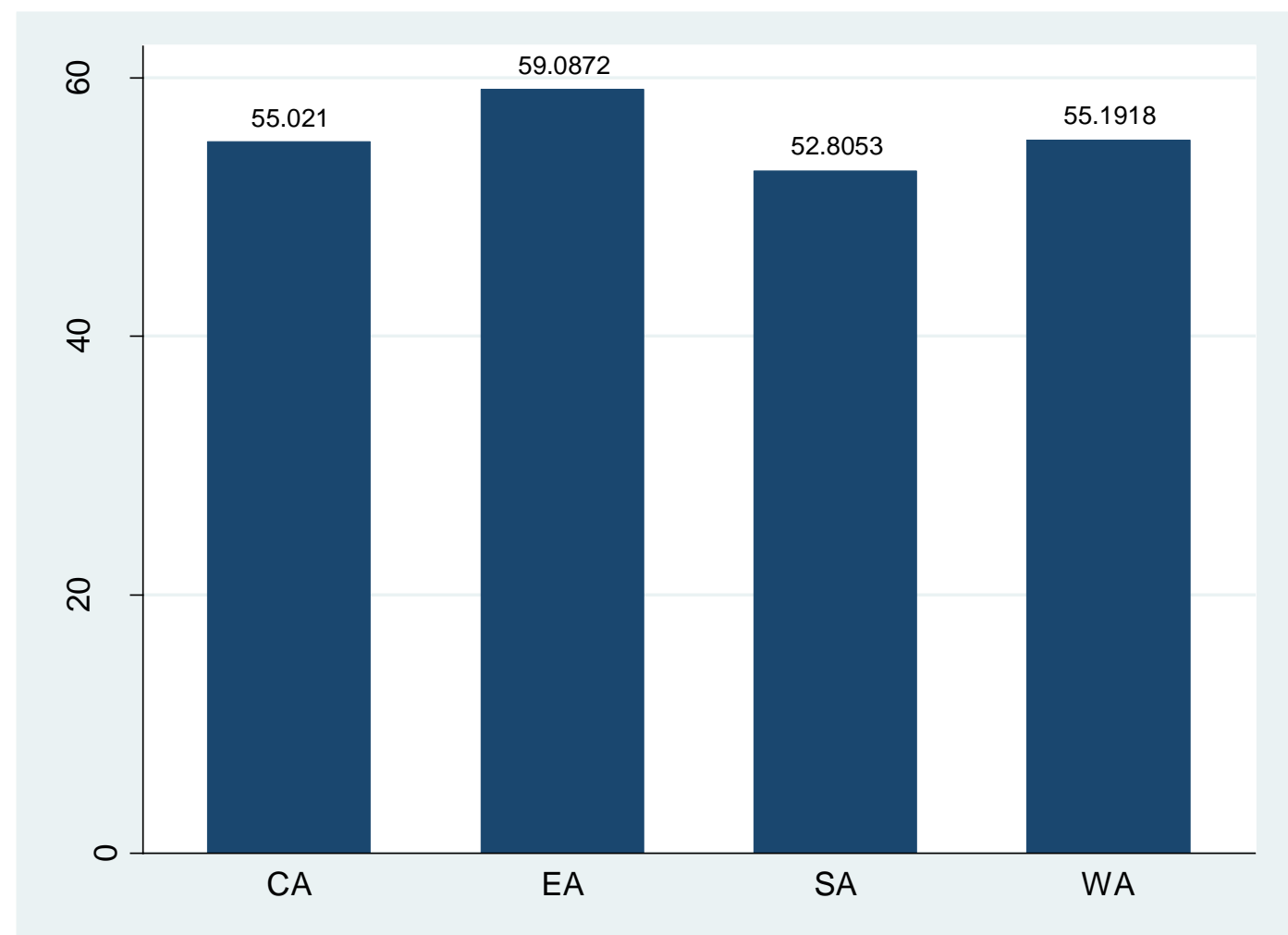

Figure-2. Mean Life Expectancy and Sub-Regions. Note: $\mathrm{CA}=$ Central Africa, $\mathrm{EA}=$ East Africa, $\mathrm{SA}=$ Southern Africa, $\mathrm{WA}=$ West Africa.

Table-2. Comparison of the variables across sub regions

\begin{tabular}{l|c|c|c|c|c|c|c}
\hline & \multicolumn{7}{c}{ Variables } \\
\hline Sub-regions & LE & INF & GDPC & COE & FPI & HCI & HE \\
\hline Central Africa & 55.02 & 12.19 & 2274.77 & 0.78 & 110.92 & 1.86 & 6.35 \\
\hline East Africa & 59.09 & 8.82 & 1439.9 & 0.52 & 110.65 & 1.81 & 3.56 \\
\hline Southern Africa & 52.89 & 13.17 & 3362.66 & 1.14 & 112.1 & 2.08 & 6.50 \\
\hline West Africa & 55.19 & 6.93 & 956.7 & 0.35 & 112.33 & 1.57 & 5.70 \\
\hline
\end{tabular}

\subsection{Data}

To evaluate the impact of socio-economic variables on life expectancy in SSA economies, this research will rely on data from the World Bank development indicators and the Penn World Table. Specifically, life expectancy, GDP per capita, $\mathrm{CO}_{2}$ emission, food production index and health expenditure were gotten from the World Bank. Human capital index was sourced from the Penn World Table. The data is for 28 SSA countries, spanning from $2000-$ 2016.

Life expectancy: this predict the number of years a new born infant would survive if the existing rate of mortality at the time of birth were to be constant in its entire life time.

Inflation rate: it is the annual percentage changes in consumer price. It is measured by the consumer price index.

GDP per capita: this is the GDP divided by the members of the population. It is measured in US dollars.

$\mathrm{CO}_{2}$ emission: it includes the discharge of carbon dioxide from burning of fossil fuel, cement production, automobiles, machines and gas flaring. It is measured in metric tons

Food production index: this includes all food items that have nutrition value and edible. It excludes tea and coffee. This is expected to have a positive relationship with life expectancy since an increase in nutrition intake will enhance good health and promote longevity. 
Human capital index: this index is measured according to the years of schooling and the yield to education.

Health expenditure: this is measured as health expenditure as a percentage of GDP. Health expenditure include health care goods and services consumed annually. It does not include spending on buildings, machinery, vaccines and IT.

\section{METHODOLOGY}

This study will adopt a health production function based on Grossman (1972) model that deals with social, economic and environmental factors as inputs of health production function but with some methodological creations that will have a significant effect on the outcome thereby aiding the long-run and short-run dynamics.

\section{$L E=f(I N F, G D P P C, C O E, F P I, H C I H E)$}

Equation 1 is a panel representation of the model across countries and time. The dependent variable is life expectancy $\left(L E_{i, t}\right)$ and the independent variables are inflation $\left(I N F_{i, t}\right)$, GDP per capita $\left(G D P P C_{i, t}\right), \mathrm{CO}_{2}$ emission $\left(C O E_{i, t}\right)$, food production index $\left(F P I_{i, t}\right)$, human capital index $\left(H C I_{i, t}\right)$ and health expenditure $\left(H E_{i, t}\right)$. Each variable is measured for a particular country $i$ at time $t$.

$$
L E_{i, t}=\alpha_{0}+\alpha_{1} I N F_{i, t}+\alpha_{2} G D P P C_{i, t}+\alpha_{3} C O E_{i, t}+\alpha_{4} F P I_{i, t}+\alpha_{5} H_{C I} I_{i, t}+\alpha_{6} H E_{i, t}+e_{i t}
$$

$L E_{i, t}=$ Life expectancy of country $i$ at time $t$

$I N F_{i, t}=$ Inflation rate of country $i$ at time $t$

$G D P P C_{i, t}=$ GDP per capita growth of country $i$ at time $t$

$C O E_{i, t}=$ Carbon dioxide emission of country $i$ at time $t$

$F P I_{i, t}=$ Food production index of country $i$ at time $t$

$H C I_{i, t}=$ Human capital index of country $i$ at time $t$

$H E_{i, t}=$ Health expenditure as a percentage of GDP of country $i$ at time $t$

$i=1,2,3,4,5,6,7 \ldots \ldots 28$

$t=2000,2001,2002,2003,2004, \ldots \ldots 2016$

We begin our estimation by first checking the stationarity of the variables using the Im, Pesaran, and Shin (2003) and Levin, Lin, and Chu (2002) stationarity test. This is done in order to avoid spurious regression. Thereafter, we proceed to the Pedroni cointegration test. If cointegration exist, we run the Hausman test to determine whether the pool mean group or the mean group estimators fit the data. 


\subsection{Pedroni Cointegration}

The Pedroni test is based on the Engle and Granger (1987) two-step residual based cointegration test. The major merit of the test is that it takes into account cross-sectional dependency especially where countries have similar outlook such as (economic, social or political) by allowing considerable heterogeneity. This test produces seven test statistics with a null hypothesis of no cointegration. The test statistics are divided into panel statistics and group statistics. The decision rule is that if the panel V statistics goes to positive infinity, the null of no cointegration is rejected. Rejection of the null hypothesis also implies that majority of the cross-sections have statistics deviated from the means.

We proceed to perform the Hausman test to determine the most efficient estimator between the mean group and the pool mean group estimator.

\subsection{Pool Mean Group}

This estimator is a form of an autoregressive distributed lag (ARDL) model proposed by Pesaran, Shin, and Smith (1999) that involves both pooling and averaging the variables. It generates consistent estimates of the mean of short-run and long-run coefficients by taking simple average of individual unit coefficients. This model has the advantage of accounting for heterogeneity between life expectancy and the different explanatory variables. The model can give efficient and consistent estimates even with different orders of integration i.e. a mixture of $\mathrm{I}(\mathrm{O})$ and I(1). The model is able to estimate long-run and short-run estimates at the same time. The pool mean group model for this study is represented as:

$$
\begin{aligned}
& \Delta L E_{i t}=\mathrm{B}_{i 0}+\phi L E_{i t-1}+\mathrm{B}_{i 1} I N F_{i t-1}+\mathrm{B}_{i 2} G D P C_{i t-1}+\mathrm{B}_{i 3} C O E_{i t-1}+\mathrm{B}_{i 4} F P I_{i t-1}+ \\
& \mathrm{B}_{i 5} H C I_{i t-1}+\mathrm{B}_{i 6} H E_{i t-1}+\sum_{j=1}^{p-1} \lambda_{i j} \Delta I N F_{i t-1}+\sum_{j=0}^{q-1} \lambda_{i j}^{1} \Delta G D P C_{i, t-j}+\sum_{j=0}^{q-1} \delta_{i j}^{2} \Delta C O E_{i, t-j}+ \\
& \sum_{j=0}^{q-1} \delta_{i j}^{3} \Delta F P I_{i, t-j}+\sum_{j=0}^{q-1} \delta_{i j}^{4} \Delta H C I_{i, t-j}+\sum_{j=0}^{q-1} \delta_{i j}^{5} \Delta H E_{i, t-j}+\lambda E C T_{t-1}+u_{i}+\varepsilon_{i t}
\end{aligned}
$$

Equation 2 is the pool mean group model that presents the variables in short-run and long-run. The variables with the difference operator are the short-run variables while those without the difference operator are the long-run variables.

\section{RESULTS}

Table 3 is the result of the panel unit root test by the Im et al. (2003) and by Levin et al. (2002). Both results show all the variables are integrated of order zero and order one which is suitable for ARDL analysis.

Table-3. Panel unit root result for SSA.

\begin{tabular}{c|c|c|c|c}
\hline & \multicolumn{2}{|c|}{ IPS Unit Root Test } & \multicolumn{2}{c}{ LLC Unit Root Test } \\
\hline Variables & t* Statistics & Order of integration & t* statistics & Order of integration \\
\hline LE & $-3.44^{* * *}$ & $\mathrm{I}(1)$ & $-6.38^{* * *}$ & $\mathrm{I}(0)$ \\
\hline INF & $-4.78^{* * *}$ & $\mathrm{I}(0)$ & $-2.08^{*}$ & $\mathrm{I}(1)$ \\
\hline GDPC & $-1.88^{* *}$ & $\mathrm{I}(1)$ & $-5.00^{* * *}$ & $\mathrm{I}(0)$ \\
\hline COE & $-4.96^{* * *}$ & $\mathrm{I}(1)$ & $-2.08^{* *}$ & $\mathrm{I}(1)$ \\
\hline FPI & $-3.77^{* * *}$ & $\mathrm{I}(1)$ & $-2.73^{* * *}$ & $\mathrm{I}(0)$ \\
\hline HCI & $-9.69^{* *}$ & $\mathrm{I}(0)$ & $-3.77^{* *}$ & $\mathrm{I}(0)$ \\
\hline HE & $-3.99^{* * *}$ & $\mathrm{I}(1)$ & $-2.40^{* *}$ & $\mathrm{I}(1)$ \\
\hline
\end{tabular}

Note: Im, Peseran and Shin (IPS); Levin, Lin and Chu (LLC) $\quad$ **** $\mathrm{p}<0.01,{ }^{*} * \mathrm{p}<0.05,{ }^{*} \mathrm{p}<0.1$.

We proceed to test for cointegration using the Pedroni's cointegration test. The result is shown in Table 4. 
Table-4. Pedroni Cointegration.

\begin{tabular}{c|c|c}
\hline Test statistics & Panel & Group \\
\hline V & 1.025 & \\
\hline Rho & 4.719 & 6.642 \\
\hline T & -1.314 & -2.40 \\
\hline ADF & 7.204 & 9.285 \\
\hline
\end{tabular}

From the Pedroni's cointegration test, the panel V statistics is a positive to infinity in absolute terms. The panel exhibit cointegration among the variables. The null hypothesis of no cointegration is rejected in panel and group statistics.

We use the Hausman test to determine the most appropriate estimator between the pool mean group and the mean group.

Table-5. Hausman Test.

\begin{tabular}{c|c|c|c|c}
\hline & \multicolumn{2}{|c|}{ Coefficients } & & \\
\hline Variables & $(\mathbf{b}) \mathbf{M g}$ & $\mathbf{( B )} \mathbf{p m g}$ & $\mathbf{b}-\mathbf{B}$ Difference & SE \\
\hline INF & -0.0055 & 0.0036 & -0.0091 & -0.0349 \\
\hline GDPC & -0.0014 & 0.0006 & -0.0021 & 0.0038 \\
\hline COE & 0.0004 & -0.0043 & 0.0008 & 0.0041 \\
\hline FPI & -0.0111 & 0.0052 & -0.0163 & 0.0140 \\
\hline HCI & -0.1179 & 0.0153 & -0.1332 & 0.2221 \\
\hline HE & 0.0002 & -0.0002 & 0.0004 & 0.0009 \\
\hline Note:
\end{tabular}

Ho: difference in coefficients not systematic.

Prob. $>$ chi2 $=0.8264$

From the test, we had a probability value of 0.83 . Therefore, the null hypothesis of homogeneity cannot be rejected (see Table 5). Hence the model supports the pool mean group estimator. From the outcome of the Hausman test, we estimate the model using the pool mean group estimator. The outcome is shown in Table 6.

Table-6. Pool mean group estimation.

\begin{tabular}{|c|c|}
\hline \multicolumn{2}{|l|}{ Long-run coefficients } \\
\hline INF & $-0.189 *(0.0172)$ \\
\hline GDPC & $0.257 * * *(0.0064)$ \\
\hline $\mathrm{COE}$ & $-3.266 * *(7.8602)$ \\
\hline FPI & $0.347 *(0.337)$ \\
\hline $\mathrm{HCI}$ & $2.719 *(6.071)$ \\
\hline $\mathrm{HE}$ & $0.493^{* *}(0.189)$ \\
\hline \multicolumn{2}{|l|}{ Short -run coefficients } \\
\hline ECT & $-0.106 *(0.0055)$ \\
\hline $\mathrm{D}(\mathrm{INF})$ & $-0.293(0.031)$ \\
\hline $\mathrm{D}(\mathrm{GDPC})$ & $0.486^{* *}(0.234)$ \\
\hline $\mathrm{D}(\mathrm{COE})$ & $-1.067 *(1.089)$ \\
\hline $\mathrm{D}(\mathrm{FPI})$ & $0.646(0.293)$ \\
\hline $\mathrm{D}(\mathrm{HCI})$ & $0.265 *(0.311)$ \\
\hline $\mathrm{D}(\mathrm{HE})$ & $0.476^{* *}(0.574)$ \\
\hline $\mathrm{C}$ & $-8.631 * *(4.335)$ \\
\hline
\end{tabular}

Table 6 presents the long-run coefficients, short-run coefficients and the error correction term for the pool mean group estimator for the Sub-Saharan Africa. Inflation rate in the short-run has significant effect on life expectancy. However, in the long-run inflation rate has a negative relationship with life expectancy. This is significant at $10 \%$. GDP per capita in both short-run and long-run exhibit positive influence on life expectancy. A rise in carbon dioxide emission in the short-run and long-run is capable of reducing life expectancy in SSA. It is 
significant at $10 \%$ in the short-run and 5\% in the long-run. This finding supports the results from Ali and Ahmad (2016). Food production in the short-run is insignificant in determining life expectancy. While in the long-run, a rise in food production can enhance life expectancy. The result corroborates with studies of Bayati et al. (2013); Halicioglu (2011). An increase in human capital index in the short-run and the long-run can increase longevity. This is significant at $10 \%$. Health expenditure in the short-run and long-run have a positive relationship with life expectancy. This outcome substantiates the works of Jaba et al. (2014); Shahbaz et al. (2016). The error correction term is -0.106 and it is statistically significant. This infers that, SSA adjust to its long-run equilibrium of life expectancy according to the changes in the independent variables by about $10.6 \%$ in the next period

\section{CONCLUSION AND POLICY RECOMMENDATIONS}

In this paper, we examined some determinants of life expectancy in sub-Saharan Africa and why it matters. We presented stylized facts about life expectancy in SSA and compared it with the different sub-regions. Pedroni cointegration test was used to determine the long-run relationship of the variables. The pool mean group estimation was used to estimate the long-run and short-run coefficients. The empirically verified findings are as follows: the rise in inflation and increase in $\mathrm{CO}_{2}$ emission aggravates life expectancy. GDP per capita, food production, human capital and health expenditure promotes life expectancy. We proffer the following recommendations from the study.

Health expenditure: in order to improve health care system in SSA there should be deliberate effort by various government to increase the public health spending. Increase spending will enhance the provision of equipment, technology and the man power, making easy accessibility to health service possible. It will also boost the motivation of health care workers. An adequately funded health system will support research which will lead to discovery of cure for numerous ailments.

$\mathrm{CO}_{2}$ emission: there should be a policy on the part of government that will stop the emission of $\mathrm{CO}_{2}$. $\mathrm{More}$ efficient locomotives that are free from $\mathrm{CO}_{2}$ should be used. And gas flaring in whatever form should stop. This will enhance conducive atmosphere and promote healthy living. Deforestation should be discouraged and massive tree planting programs should be adopted. This has the capacity of providing more oxygen to the environment.

Food Production: some parts of the SSA are experiencing shortage of food. To increase food production the right agricultural practices, combine with technology can boost food production. Farmers, most especially in the rural areas should be informing about improved practices and discoveries that will enhance yield. Government should at all times should ensure the availability of food (through local production or import) in the strategic food reserves. This will lessen the impact of food shortages caused by famine.

Income: we discovered that higher income is associated to long life. Higher income will improve welfare and standard of living. There should be collaborative effort by the government and private sector in job creation. Government should provide the enabling environment for private businesses to thrive. This will ensure that individuals have income to support their health when the need arise.

Inflation: in order to control inflation, government should strive to maintain long-run consistency between monetary and fiscal policies. Humans are averse to uncertainties and drastic rise in price level.

Human capital: to boost human capital, individuals need to acquire more education, more skills and more experiences that will enable them enjoy long life. Government needs to support education by making it available and affordable.

Funding: This study received no specific financial support.

Competing Interests: The authors declare that they have no competing interests.

Acknowledgement: Authors would like to commend the editors and two anonymous reviewers for providing insightful and constructive comments on an earlier version of this paper. 


\section{REFERENCES}

Ali, A., \& Ahmad, K. (2016). The impact of socio-economic factors on life expectancy for Sultanate of Oman: An empirical analysis. MPRA Paper No. 70871.

Amuka, J. I., Asogwa, F. O., Ugwuanyi, R. O., Omeje, A. N., \& Onyechi, T. (2018). Climate change and life expectancy in a developing country: Evidence from greenhouse gas ( $\mathrm{CO} 2)$ emission in Nigeria. International Journal of Economics and Financial Issues, 8(4), 113-119.

Bayati, M., Akbarian, R., \& Kavosi, Z. (2013). Determinants of life expectancy in eastern mediterranean region: A health production function. International Journal of Health Policy and Management, 1(1), 57-61. Available at: https://doi.org/10.15171/ijhpm.2013.09.

Bloom, D. E., Sachs, J. D., Collier, P., \& Udry, C. (1998). Geography, demography, and economic growth in Africa. Brookings Papers on Economic Activity, 1998(2), 207-295. Available at: https://doi.org/10.2307/2534695.

Cliff, A., Peter, H., \& Mathew, S. (2004). World atlas of epidemic diseases. London: Oxford University Press.

Engle, R. F., \& Granger, C. W. (1987). Co-integration and error correction: Representation, estimation, and testing. Econometrica: Journal of the Econometric Society, 55(2), 25 1-276. Available at: https://doi.org/10.2307/1913236.

Fayissa, B., \& Gutema, P. (2005). Estimating a health production function for Sub-Saharan Africa (SSA). Applied Economics, $37(2)$, 155-164. Available at: https://doi.org/10.1080/00036840412331313521.

Forbes, J. F., \& McGregor, A. (1984). Unemployment and mortality in post-war Scotland. Journal of Health Economics, 3(3), 239257. Available at: https://doi.org/10.1016/0167-6296(84)90013-4.

Grossman, M. (1972). The demand for health. A theoretical and empirical investigation. New York: NBER.

Halicioglu, F. (2011). Modeling life expectancy in Turkey. Economic Modelling, 28(5), 2075-2082.

Husain, A. R. (2002). Life expectancy in developing countries: A cross-section analysis. The Bangladesh Development Studies, 28(1/2), 161-178.

Im, K. S., Pesaran, M. H., \& Shin, Y. (2003). Testing for unit roots in heterogeneous panels. Journal of Econometrics, 115(1), 5374.

Jaba, E., Balan, C. B., \& Robu, I.-B. (2014). The relationship between life expectancy at birth and health expenditures estimated by a cross-country and time-series analysis. Procedia Economics and Finance, 15, 108-114. Available at: https://doi.org/10.1016/s22 12-5671(14)00454-7.

Kabir, M. (2008). Determinants of life expectancy in developing countries. The journal of Developing areas, 41(2), 185-204.

Keita, M. (2013). Standards of living and health status: The socioeconomic determinants of life expectancy in Sub-Saharan Africa. MPRA, No. 57553.

Levin, A., Lin, C.-F., \& Chu, C.-S. J. (2002). Unit root tests in panel data: Asymptotic and finite-sample properties. Journal of Econometrics, $108(1), 1-24$.

Mathijs, V. D. (2014). Financial crises reduce life expectancy. Professorial Inaugural Lectures. Rotterdam School of Management. Erasmus University Rotterdam.

McKeown, T. (1997). The modern rise of population. London: Butler and Tanner.

Miller, R. D., \& Frech, H. (2000). Is there a link between pharmaceutical consumption and improved health in OECD countries? Pharmacoeconomics, 18(1), 33-45. Available at: https://doi.org/10.2165/00019053-200018001-00006.

Monsef, A., \& Mehrjardi, A. S. (2015). Determinants of life expectancy: A panel data approach. Asian Economic and Financial Review, 5(11), 1251-1257. Available at: https://doi.org/10.18488/journal.aefr/2015.5.11/102.11.1251.1257.

Ngangue, N., \& Manfred, K. (2015). The impact of life expectancy on economic growth in developing countries. Asian Economic and Financial Revierw, 5(4), 653-660.

Pesaran, M. H., Shin, Y., \& Smith, R. P. (1999). Pooled mean group estimation of dynamic heterogeneous panels. Journal of the American statistical Association, 94(446), 62 1-634. Available at: https://doi.org/10.1080/01621459.1999.10474156.

Roff, D. (2002). Life history evolution. Sunderland: Sinaheur. 
Sede, P. I., \& Ohemeng, W. (2015). Socio-economic determinants of life expectancy in Nigeria (1980-2011). Health Economics Review, 5(1), 1-11. Available at: https://doi.org/10.1186/s13561-014-0037-z.

Shahbaz, M., Loganathan, N., Mujahid, N., Ali, A., \& Nawaz, A. (2016). Determinants of life expectancy and its prospects under the role of economic misery: A case of Pakistan. Social Indicators Research, 126(3), 1299-1316.

Yavari, K., \& Mehrnoosh, M. (2006). Determinants of life expectancy: A cross-country analysis. Iranian Economic Review, 11 (15), $131-142$. 